\title{
Research on the Vibration Insulation of High-Speed Train Bogies in Mid and High Frequency
}

\author{
Jia Liu (iD) ${ }^{1,2}$ and Xuesong Jin (iD) \\ ${ }^{1}$ State Key Laboratory of Traction Power, Southwest Jiaotong University, Chengdu 610031, China \\ ${ }^{2}$ Science and Technology on Reactor System Design Technology Laboratory, Nuclear Power Institute of China, Chengdu 610213, China \\ Correspondence should be addressed to Xuesong Jin; xsjin@home.swjtu.edu.cn
}

Received 24 September 2017; Accepted 24 December 2017; Published 13 February 2018

Academic Editor: Evgeny Petrov

Copyright ( 2018 Jia Liu and Xuesong Jin. This is an open access article distributed under the Creative Commons Attribution License, which permits unrestricted use, distribution, and reproduction in any medium, provided the original work is properly cited.

According to a large amount of the test data, the mid and high frequency vibrations of high-speed bogies are very notable, especially in the $565 \sim 616 \mathrm{~Hz}$ range, which are just the passing frequencies corresponding to the 22nd to 24th polygonal wear of the wheel. In order to investigate the main cause of wheel higher-order polygon formation, a 3D flexible model of a Chinese high-speed train bogie is developed using the explicit finite element method. The results show that the couple vibration of bogie and wheelset may lead to the high-order wears of wheel. In order to reduce the coupled resonance of the wheelset and the bogie frame, the effects of the stiffness and damping of the primary suspensions, wheelset axle radius, and bogie frame strength on the vibration transmissibility are discussed carefully. The numerical results show that the resonance peaks in high frequency range can be reduced by reducing the stiffness of axle box rotary arm joint, reducing the wheelset axle radius or strengthening the bogie frame location. The related results may provide a reference for structure improvement of the existing bogies and structure design of the new high-speed bogies.

\section{Introduction}

Nowadays more and more people consider high-speed trains to be a comfortable, safe, low, and clean energy consumption transportation tool. However, increasing the operation speed and mileage accelerated the polygonal wear of high-speed train wheels, which leads to the fierce vibration of the vehicletrack system in a wide frequency range. According to site tests and experiences of the authors, the high-order polygonal wear of wheel and the mid and high frequency vibrations of high-speed bogies are very notable [1]. These mid and high frequency vibration behavior existing in bogie frames have been considered to accelerate high-order polygonal wear of high-speed train wheels. To slow down the development of wheel polygon and offer a comfortable vibration environment for the high-speed train, it is necessary to investigate the dynamic characteristics of primary suspension and the structure parameters of bogie components on the vibration transmissibility of a high-speed bogie system. This study can provide a basis for high-speed vibration reduction in mid and high frequency.

The multibody modeling and dynamic behavior of the railway vehicles are well understood in the low frequency range, and the wheelset can be modeled well in the frequency range up to several thousand Hertz [2]. However, the work focused on middle and high frequency vibration of railway bogies and its influence on the system dynamics is relatively insufficient. Alexander et al. [3] established a FE model of the whole bogie, this model covers a high number of beams and bars, and most of the primary suspensions and secondary suspensions are simplified in this model. The model mainly serves as a support to investigate the actuator performance and evaluate several actuator concepts. Ren et al. [4] built a flexible vehicle system dynamics model based on multibody modeling and FE method, which was used to investigate the vibration and frequency transmission characteristics of the high-speed EMU. The vibration transference from axle box to car body was analyzed in detail. 
In order to reduce the vibrations of the high-speed bogie in in mid and high frequency, a 3D flexible model of a Chinese high-speed train bogie is developed using the explicit finite element (FE) method. Based on the bogie FE model, the vertical vibration responses of the axle boxes and the bogie frame are obtained in frequency domains. The reasons which cause the high-order wear of wheel are analyzed, and the effects of the parameters of the primary suspensions, wheelset axle radius, and stiffened thin plates in bogie frame on the vibration transmissibility are discussed carefully. It is noted that the numerical methods and the results would be helpful in understanding the mid and high frequency vibration characteristics and the vibration transmissibility of the high-speed train bogie.

\section{Measurement of Wheel Polygon and Vehicle Vibration}

Both wheel polygon and vehicle vibration of the trailer bogie were tested. Wheel polygon measurements before and after reprofiling were completed while the bogies were standing on the rail. Vibrations of the axle box and the bogie frame before reprofiling were monitored while the train was running at the speed of $250 \mathrm{~km} / \mathrm{h}$.

2.1. Characteristic of Wheel Polygon. The wheel polygon can cause a series of vibration and noise problems of high-speed train according to a lot of previous test data. Therefore, the wheel roughness of the wheel circumference was tested firstly. Test of wheel polygon was carried out by OSD-RRM01 [1, 5]. Displacement sensors were installed vertically to wheel treads, to record the wheel diameter difference. Rotation sensors were used to measure the circumference of wheel, in order to record the wheel polygon orders exactly.

The wheel roughness is defined with logarithmic form $L$ :

$$
L=20 \log _{10} \frac{r_{n}}{r_{\text {ref }}}
$$

where $r_{n}$ is wheel roughness in different order and $r_{\text {ref }}$ is reference of the wheel diameter difference, usually being $1 \mu \mathrm{m}$.

The polygon order distributions before and after reprofiling are compared in Figure 1. The horizontal axis illustrates the polygon orders and the vertical axis denotes the amplitudes of the wheel polygons. The peaks mean that the corresponding polygons have a large contribution to the uneven wear of the wheels. Figure shows that the roughness of the wheel before reprofiling is very large, especially the 22nd to 24th polygonal wear of the wheel. After reprofiling, the roughness level of the 5th to 24th polygon reduces evidently, but peaks at the ordinates from 22 to 24 are still high. In the processing of profiling, higher-order polygons are reserved because the tool head does not contact with wave valley segment of polygonal wear.

2.2. Vibration of Vehicle. Figure 2 gives the test photo of bogie vibration. Two accelerates were fixed on the axle box and the bogie frame, respectively, to measure the vertical

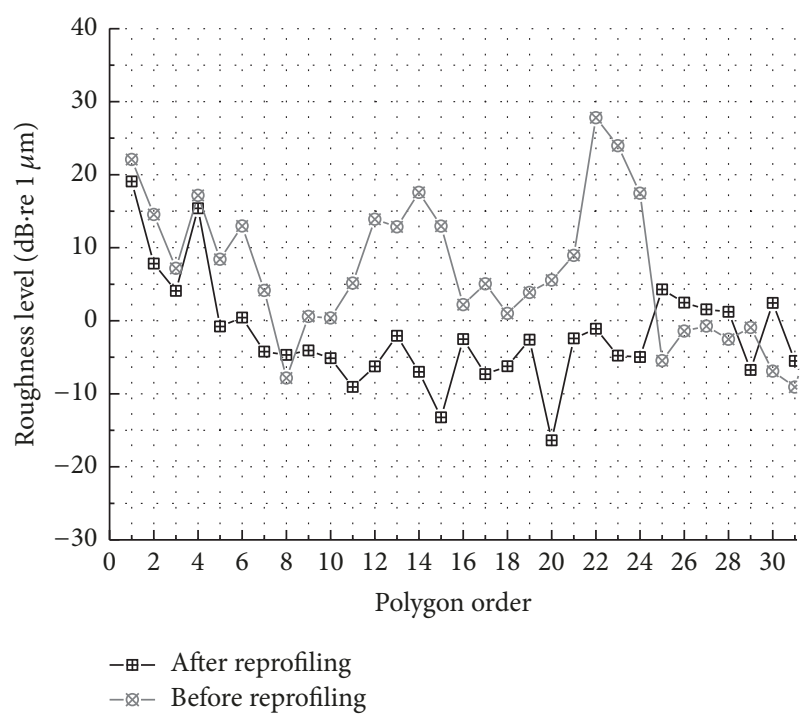

FIGURE 1: Wheel polygon order.

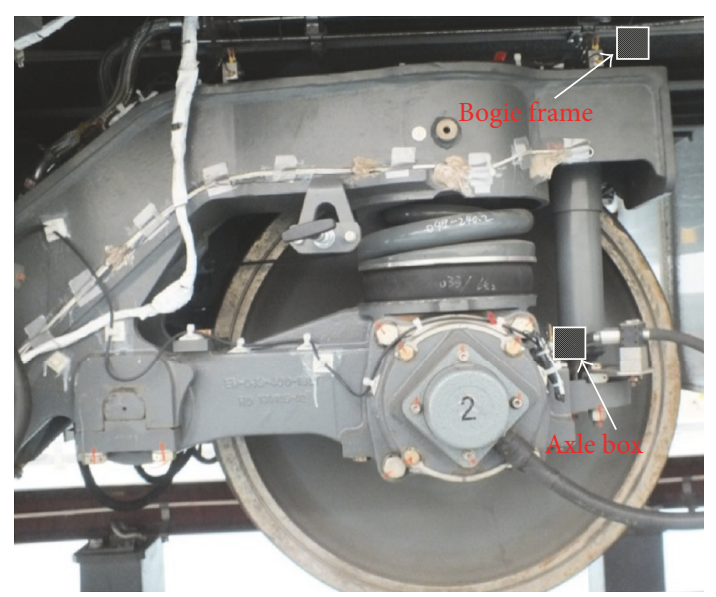

FIgURE 2: Test photo of accelerations installed on the bogie frame and axle box.

vibration of the bogie. The vibration data was acquired by using B\&K Type 3560D hardware. The sampling frequency and the sampling numbers are $3200 \mathrm{~Hz}$ and 800 , respectively. The high-speed train was running on a straight track and its speed was $250 \mathrm{~km} / \mathrm{h}$.

Figure 3 shows the vibration results of the axle box and the bogie frame before reprofiling. There is an obvious reduction in the vibration from the axle box to the bogie frame, especially in the frequency band of $650 \sim 800 \mathrm{~Hz}$. In the $565 \sim 616 \mathrm{~Hz}$ range, magnitudes of serious vibrations on the axle box are close to that of the bogie frame. Here, frequencies in the band $565 \sim 616 \mathrm{~Hz}$ are just the passing frequencies corresponding to the 22nd to 24th polygonal wear of the wheel. Hence, measures should be taken to improve the vibration isolation in this frequency band for slowing down the development of the wheel polygonal wear. The vibration isolation can be increased by optimizing either the parameters of primary suspension or the structure of 


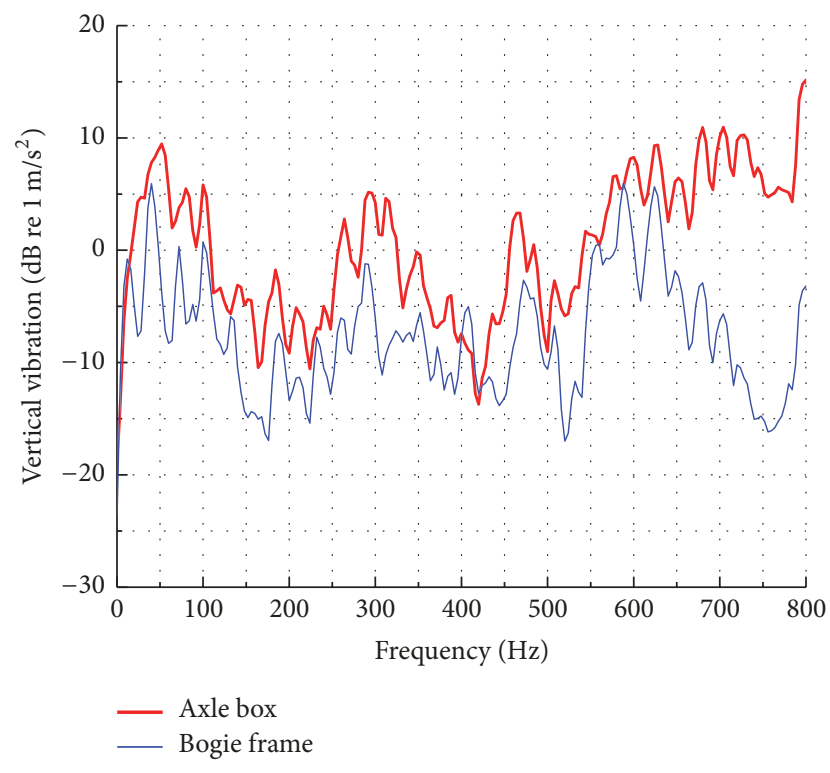

FIgURE 3: Vibrations of bogie frame and axle box.

the bogie. In this paper, the material parameters that affect the vibration transmissibility of the primary suspension components are analyzed.

When wheel rotates a circle, the rotating frequency $f_{0}$ is given by

$$
f_{0}=\frac{v}{\pi D}=\frac{250 \mathrm{~km} \cdot \mathrm{h}^{-1}}{0.86 \mathrm{~m} \times 3.14 \times 3.6}=25.7 \mathrm{~Hz},
$$

where the wheel diameter $D$ is $0.86 \mathrm{~m}$. lated by

The passing frequency of the wheel polygon $f_{n}$ is calcu-

$$
f_{n}=n f_{0}=25.7 n,
$$

where $n$ is the polygon order.

\section{Flexible Model of the Bogie and Its Validation}

3.1. Flexible Bogie Model. Figure 4 indicates the 3D transient finite element (FE) model of the entire bogie system, which consists of two wheelsets, a bogie frame, and a series of the primary suspension parts, developed with ANSYS. The primary suspension parts include eight coil springs (inside spring and outside spring), four rubber bearings under the coil springs, four axle box rotary arms, four rotary arm rubber joints, four vehicle primary dampers, and eight rubber joints above or below the dampers. All the geometries of this bogie system are the same as that of the previously tested trailer. The brake disc on the wheelsets and the brake disc seat on the bogie frame are also considered in this study.

Figure 5 shows the FE model of some of the primary suspension components. The figures in the left- and righthand sides are the 3D geometries and the FE model, respectively. From Figure 5, it can be observed that the nonlinear

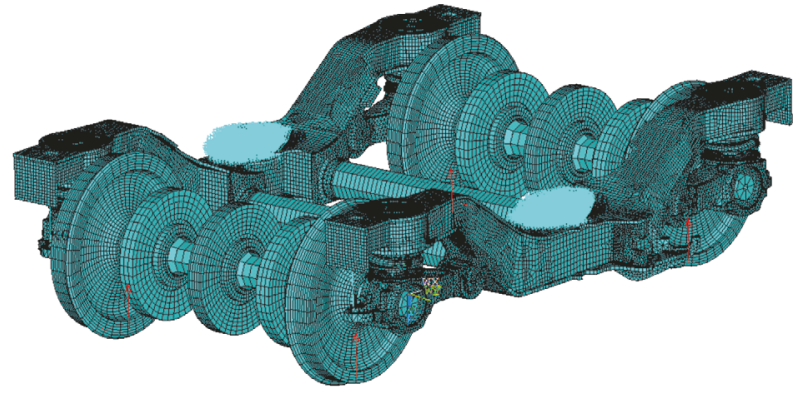

FIGURE 4: FEM of the whole bogie system.

influences of rubber materials are ignored. The rotary arm rubber joint, the rubber bearing, and the damper rubber joint are simulated using spring-damper elements [6]. The vehicle damping is simulated using damper elements. The car body is simulated as a lumped mass connected to the bogie frame through secondary suspension. The secondary suspension is simulated using the spring-damper elements. The axle box rotary arm and the coil spring are meshed using 3D solid elements taking their actual geometries into consideration [7]. Table 1 lists the values of the stiffness and damping involved in this paper [8].

To improve the calculating efficiency, some $1 \mathrm{D}$ and $2 \mathrm{D}$ elements are applied to the model. For example, beam elements are used to simulate bogie frame horizontal beams and axles, mass elements are used to simulate the brake disc seat on the bogie frame, and shell elements are used to simulate bogie side frames. The total element and node numbers are 234165 and 184209 , respectively.

3.2. Theory of Wheel/Track Force. Remington [9] put forward the most comprehensive single model of wheel-rail force and wheel-rail noise. The model assumes that the small-scale roughness on the running surfaces of the wheel and rail is the primary mechanism for the force generation. Included in the model are such effects as the spatial filtering of the roughness due to the finite area of contact between wheel and rail and the interaction between the wheel and rail, including local contact stiffness.

$\{r\}$ is defined as the displacement-input vector. Assuming that there are $N$ coupling coordinates, $z_{1}, \ldots, z_{N}$, one can use $r_{j}$ to represent the coupled displacements of the wheel and rail, $z_{j}^{R}$ for the rail, $z_{j}^{W}$ for wheel, and $z_{j}^{C}$ for the relative motion in the contact zone. The latter can be separated into two parts: $z_{j}^{C W}$ for local deformations of the wheel and $z_{j}^{C R}$ for the local deformations of the rail. Then

$$
z_{j}^{R}=z_{j}^{W}-z_{j}^{C W}-z_{j}^{C R}+r_{j} .
$$

The wheel and rail can each then represented by an $N$. $N$ matrix of point receptances, $\alpha_{j}^{W}$ and $\alpha_{j}^{R}$. The transfer properties of the contact zone (relative motion, $z_{j}^{C W}$ and $z_{j}^{C R}$, per unit force) can similarly be represented by receptances, 


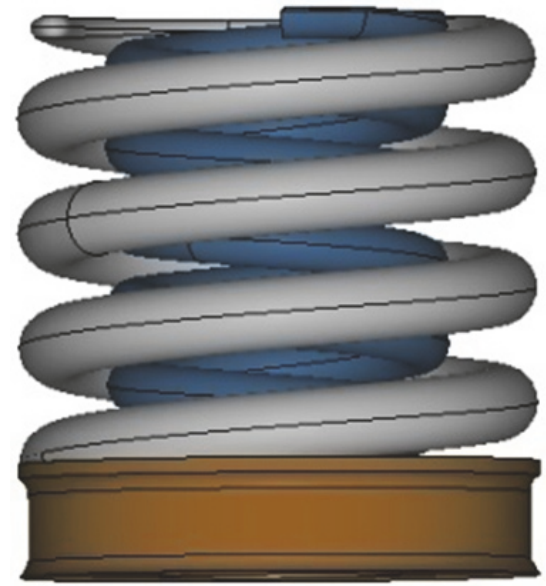

(a) Coil spring and the rubber bearing

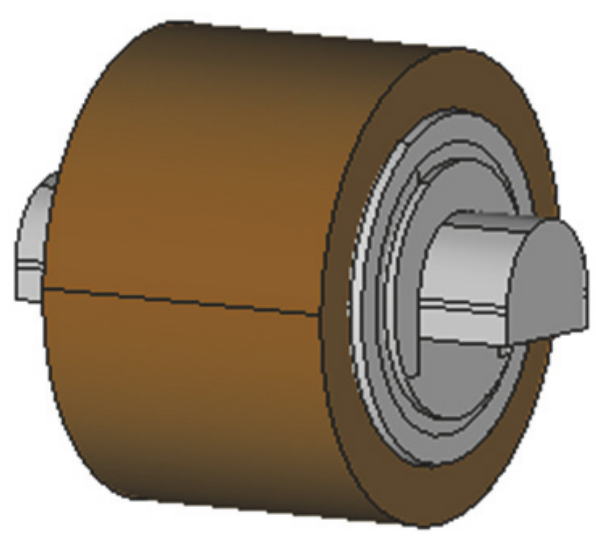

(c) Rotary arm rubber joints
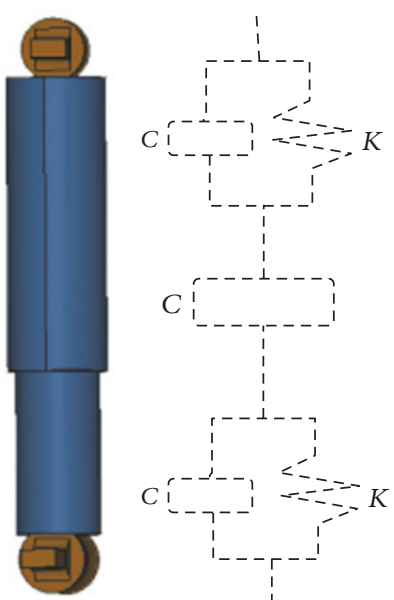

(b) Primary damper and the rubber joint

FIGURE 5: 3D geometry and FEM of the primary suspension.

TABLE 1: Values of stiffness and damping involved in this study.

\begin{tabular}{|c|c|c|c|c|c|c|}
\hline & \multicolumn{3}{|c|}{ Stiffness (N/mm) } & \multicolumn{3}{|c|}{ Damping $(\mathrm{N} \cdot \mathrm{s} / \mathrm{mm})$} \\
\hline & Vertical & Horizontal & Longitudinal & Vertical & Horizontal & Longitudinal \\
\hline \multicolumn{7}{|l|}{ Primary suspension } \\
\hline Rubber bearings & 4000 & 400 & 4000 & 0.02 & 0.02 & 0.24 \\
\hline Primary dampers & -- & -- & -- & -- & 33 & -- \\
\hline Damper rubber joints & 70000 & 7500 & 70000 & 1.66 & 0.18 & 1.66 \\
\hline Rotary arm rubber joints & 160000 & 18000 & 76000 & 9 & 0.43 & 3.79 \\
\hline Secondary suspension & 1150 & 174 & 174 & 37 & 29.4 & 245 \\
\hline
\end{tabular}

$\alpha_{j k}^{C W}$ and $\alpha_{j k}^{C R}$. An interaction force acting in the $k$ th coordinate direction, $P_{k}$, results from the coupling (the force is transmitted by the contact springs) and the same force acts on both the wheel and the rail (in opposite directions). The forces and displacements, at a specific frequency, $\omega$, can be related by the receptances of the various subsystems:

$$
z_{j}^{R}=\sum_{k=1}^{N} \alpha_{j k}^{R} P_{k}
$$

$$
\begin{gathered}
z_{j}^{W}=\sum_{k=1}^{N} \alpha_{j k}^{W}\left(-P_{k}\right), \\
z_{j}^{C R}=\sum_{k=1}^{N} \alpha_{j k}^{C R} P_{k}, \\
z_{j}^{C W}=\sum_{k=1}^{N} \alpha_{j k}^{C W} P_{k} .
\end{gathered}
$$




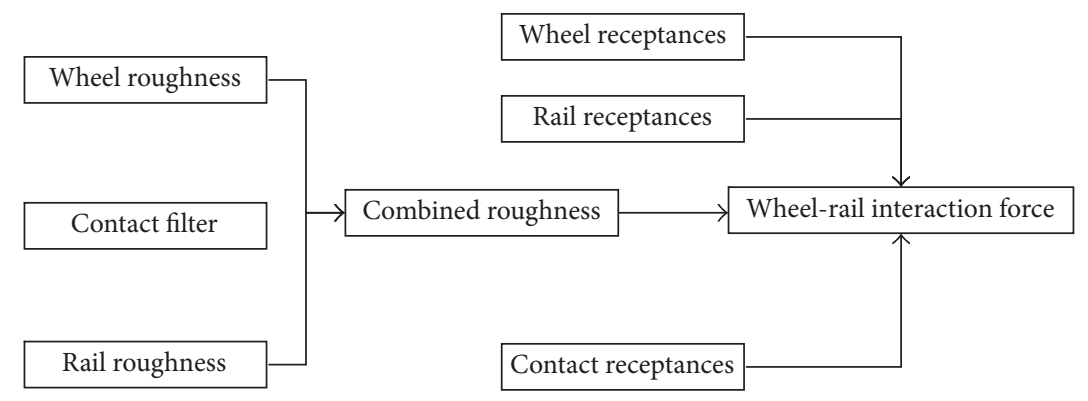

FIGURE 6: Framework of theoretical model of wheel-rail force.

Or the upper matrix can be translated to other forms:

$$
\begin{gathered}
\left\{z^{R}\right\}=\left[\alpha^{R}\right]\{P\}, \\
\left\{z^{W}\right\}=-\left[\alpha^{W}\right]\{P\}, \\
\left\{z^{C R}\right\}=\left[\alpha^{C R}\right]\{P\}, \\
\left\{z^{C W}\right\}=\left[\alpha^{C W}\right]\{P\} .
\end{gathered}
$$

Note the negative signs for the wheel, since here the force acts in the opposite direction to that of the displacement. Hence, from equation (4)

$$
\{r\}=\left[\alpha^{R}+\alpha^{C R}+\alpha^{C W}+\alpha^{W}\right]\{P\}=[\alpha]\{P\},
$$

where $[\alpha]$ is defined as the matrix of combined wheel, rail, and contact zone receptances:

$$
\{P\}=[\alpha]^{-1}\{r\} .
$$

Equation (8) is the wheel-rail force calculated model which was put forward by Thompson [10] based on Remington's model. A wheel-rail interaction model is used to calculate wheel-rail dynamic force base on the wheel-rail combined roughness. Figure 6 shows the flow chart of the progress to calculate the wheel-rail force. The wheel roughness and rail roughness are used to calculate the wheel-rail combined roughness, and then, combined with the receptances of wheel and rail, the wheel/track force is obtained.

The local deformations of two bodies in contact act as nonlinear stiffness between them. However, for small displacement, linearized Hertzian contact stiffness, $K_{v}$, in vertical direction, may be calculated as

$$
K_{v}=\left(\frac{3}{2 \xi}\right)\left[\left(\frac{4}{3} \frac{E}{1-\mu^{2}}\right)^{2} P_{0} \frac{4 R_{W} R_{R}}{R_{W}+R_{R}}\right]^{1 / 3},
$$

where $R_{W}$ is the radius of wheel and $R_{R}$ is the radius of curvature of rail surface. $E$ is the plain strain elastic, and $\mu$ is Poisson's ratio of wheel and rail. $P_{0}$ is the static component of the vertical load at the contact. $\xi$ is a dimensionless quantity dependent on the radius of curvature of the two surfaces $\left(R_{R}\right.$ and $R_{W}$ ) and hence the shape of the contact patch. $\xi$ is related to $\theta$, which is defined as follows:

$$
\theta=\operatorname{acrcos}\left|\frac{R_{R}-R_{W}}{R_{R}+R_{W}}\right| .
$$

The contact patch wavenumber filter is presented by Remington, which is given by

$$
|H(k)|^{2}=\frac{4}{\alpha(k b)^{2}} \int_{0}^{\arctan \alpha}\left[J_{1}(k b \sec x)\right]^{2} d x
$$

where $k$ is the wavenumber along the length of the rail or around the circumference of the wheel, $\alpha$ is a constant determining the degree of correlation between parallel roughness profiles at a given wavenumber, $J_{1}(x)$ is the first-order Bessel function, $x$ is a variable, and $b$ is circular contact patch of radius.

Prestress and wheel/rail contact forces are applied to the points on the four wheel treads (Figure 5). The prestress is $72000 \mathrm{~N}$ computed based on the single wheel weight of the vehicle. The wheel/rail contact forces are calculated based on the TWINS model. Rail roughness and wheel roughness were obtained by the site test results, and the measurements were conducted by using CAT and BBM, respectively. Rail receptance is obtained by using hammer, and the vertical acceleration frequency response of rail surface is obtained by exiting the same position. Acceleration is translated into displacement by using (12) in the frequency domain. Wheel receptance is obtained by using the upper $3 \mathrm{D}$ transient finite element (FE) model of the entire bogie system. Force is applied to the points on the four wheel treads; the drivingpoint and transfer-point mobility are calculated then. Figure 7 illustrates the wheel-track forces in the frequency domain; from this figure it can be shown that the wheel-track excitation energies are mainly focused on the frequency band which is under $200 \mathrm{~Hz}$ :

$$
a_{i}=-4 \pi^{2} \times f_{i}^{2} \times d_{i} \quad(i=1,2, \ldots, n),
$$

where $a_{i}$ is the acceleration in the frequency $i$ and $d_{i}$ is the displacement in the frequency $i$.

3.3. Model Validation. Based on the above FE model, the vibrations of the axle box and the bogie frame, both in time domain and frequency domain, are calculated by ANSYS. The FE model takes wheel/track force in time domain as input; the vibrations of the axle box and the bogie frame are calculated by transient dynamic analysis method. Figure 8 shows the 


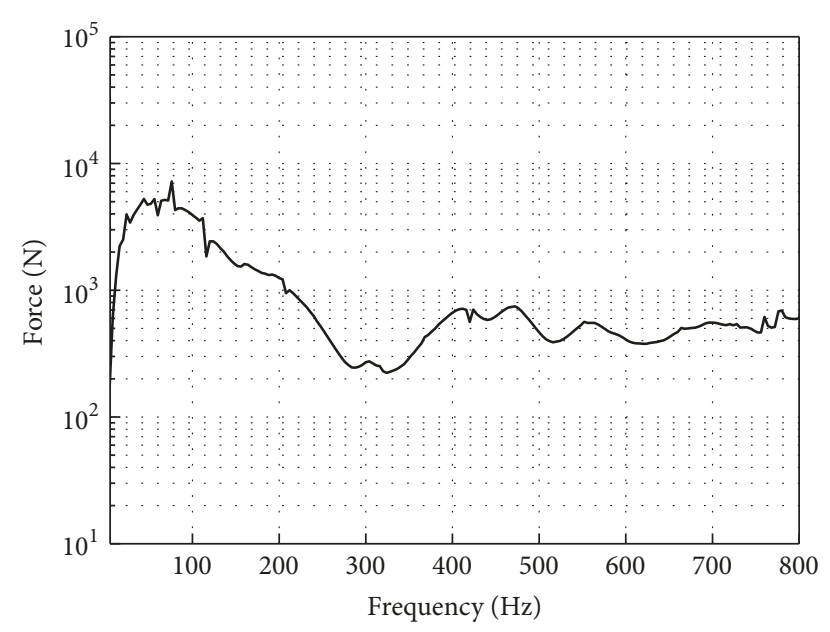

FIGURE 7: Wheel/rail contact force in frequency domain.

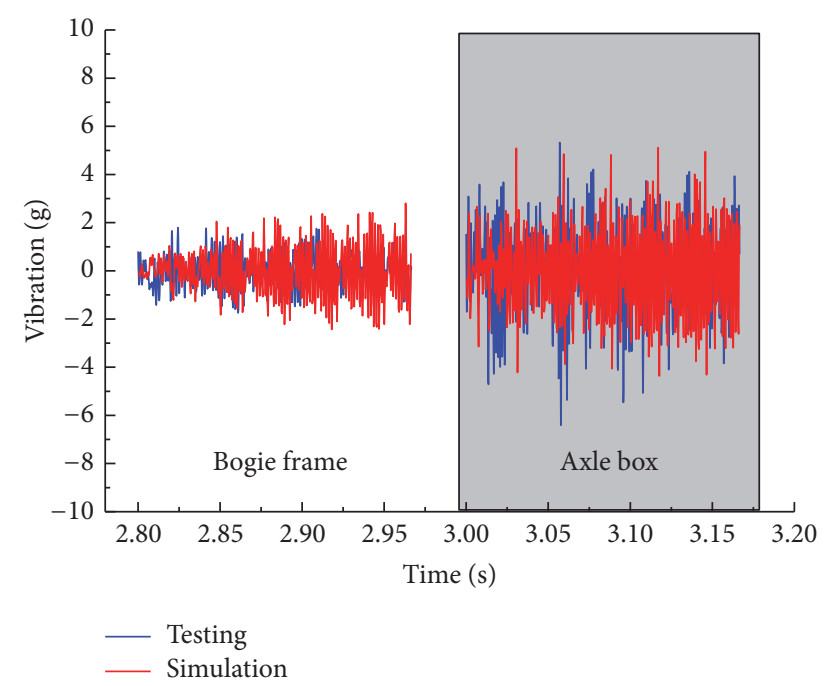

FIGURE 8: Vibration comparison of testing and simulation (in time domain).

vibration responses in time domain. Through FFT analysis, the vibrations are translated into the frequency domain below $800 \mathrm{~Hz}$. Figure 9 shows the vibration frequency spectrum. In time domain, the vibration magnitudes of bogie frame and axle box obtained by simulation are in good agreement with the measured results. In frequency domain, the spectrum distributions and vibration magnitudes of the axle box obtained by using the FE method are similar to the measurement in the frequency band of $0 \sim 800 \mathrm{~Hz}$, which validates that the model of wheelset and axle box are accurate, and the wheel/track force is close to that in practice. As for the vibration of the bogie frame, in spite of some differences in magnitudes in the frequency band of $0 \sim 800 \mathrm{~Hz}$, the spectrum distributions are in good agreement with the measured results. Thus, the FE model and the calculated method are validated effectively, and a series of investigations are conducted using this model.

\section{Vibration Analysis of Bogie Flexible Model}

Harmonic response analysis is used to calculate the steady vibration responses of bogie key components under the swept frequency excitation. Then the vibration peaks from the frequency response function are counted out. In these peak frequencies, vibration displacement color clouds of the whole bogie are invested. The car body's 6 DOFs are all constrained. The harmonic forces are applied to the points on the four wheel treads. The magnitude of the force is $50 \mathrm{~N}$, and the analysis frequency band is from $0 \mathrm{~Hz}$ to $1000 \mathrm{~Hz}$, and the frequency resolution is $4 \mathrm{~Hz}$. The calculated progress is as follows: First of all, the modal parameters and extended models are calculated. Based on the modal results, the vibrations of axle box and bogie frame are extracted by the full arithmetic. The vibration results in one-third octave of four bogie key part compartments, which are bogie over the primary damper, bogie over the spring, rotary arm support, and axle box respective, are shown as Figure 10. From this figure, it can be shown that as the frequency increased, the magnitudes of every part components of bogie raise significantly, which illustrates that as for the same wheel/track force, higher frequency is easier to excite the serious vibration. In the centre band of $500 \mathrm{~Hz}$, the magnitude of bogie frame is almost the same as axle box, which is up to $20 \mathrm{~dB}$. Vibrations of rotary arm support are the smallest. In the centre band of $630 \mathrm{~Hz}$, vibration energies of bogie frame over primary damper are bigger than axle box, axle box and rotary arm support are almost the same, and bogie frames over spring are the smallest.

Furthermore, the FFT vibrations of these four component parts in the frequency band of $400 \sim 800 \mathrm{~Hz}$ are calculated. Results are shown as Figure 11; from this picture, in the frequency band of $520 \sim 560 \mathrm{~Hz}$, magnitudes of serious vibrations on the axle box are close to that of the bogie frame. In the frequency band of 550 620 Hz, there are no obvious vibration peaks on bogie frame and axle. The vibration energies from axle box are translate into bogie frame without reduction. The vibration magnitudes of bogie frame are higher than axle box in some specific frequencies. Vibration of rotary arm support is smaller than the bogie frame, over the primary damper and over the spring, respectively. Therefore, the vibration reductions of axle box and bogie frame over the primary damper are mainly discussed in Section 5.

From Figure 11, resonance peaks of bogie system are in the frequency band of $520 \sim 560 \mathrm{~Hz}$. Therefore, the displacement color clouds of the whole bogie in this band are shown in Figure 12. In the $520 \sim 560 \mathrm{~Hz}$, the vibration deformations are mainly shown as the couple vibration of bogie side beam local movements and the third bend of wheelset. Therefore, the two modes may be the main reasons which lead to the resonance vibration in high frequency and then induce the high-order wear of wheel.

\section{Vibration Isolation Design in Mid and High Frequency}

The vibrations at three points on the bogie frame, near the vertical damper, coil spring, and the rotary arm rubber joint, 


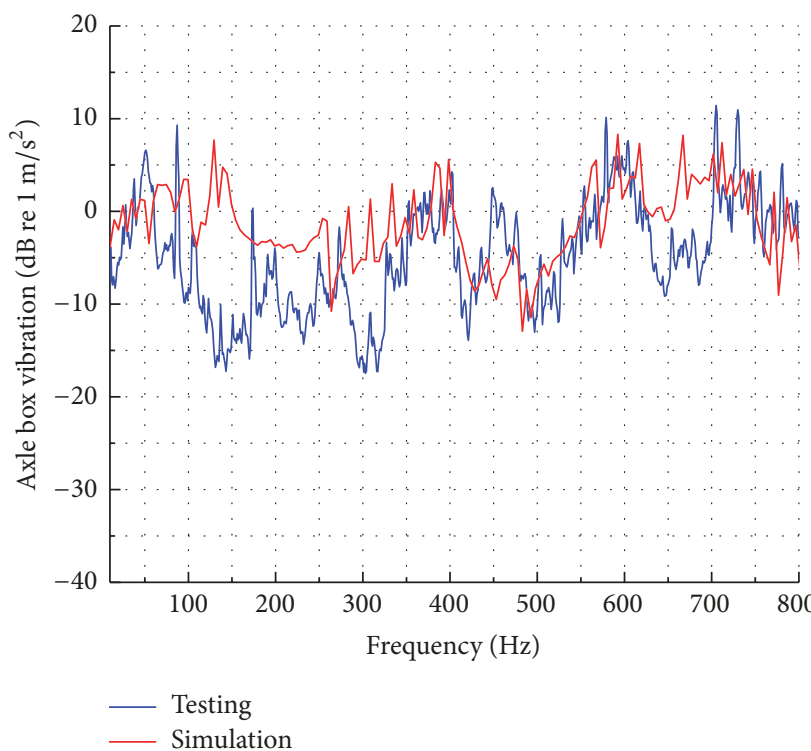

(a) Axle box

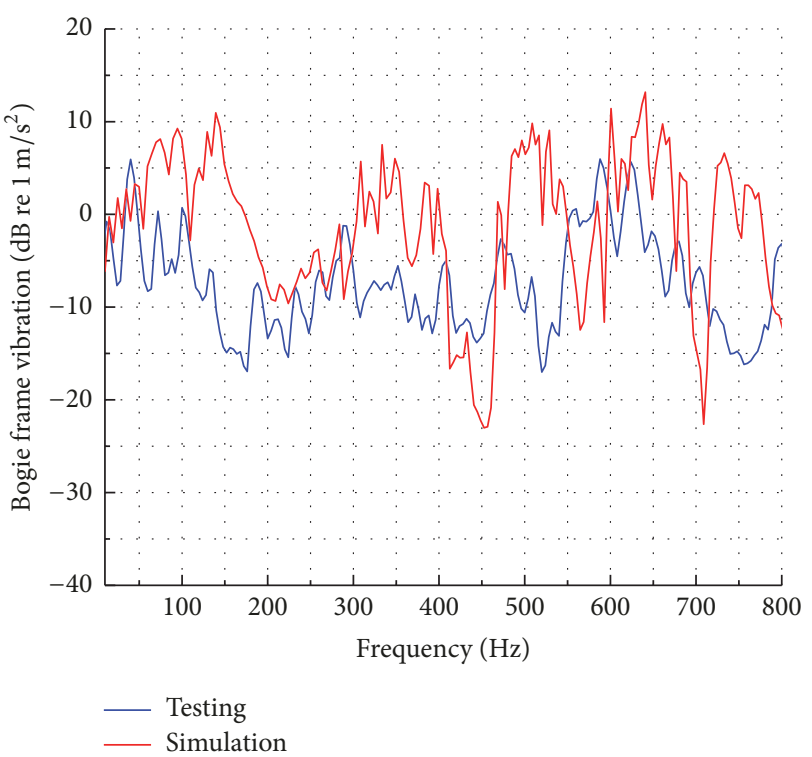

(b) Bogie frame

FIGURE 9: Vibration comparison of testing and simulation (in frequency domain).

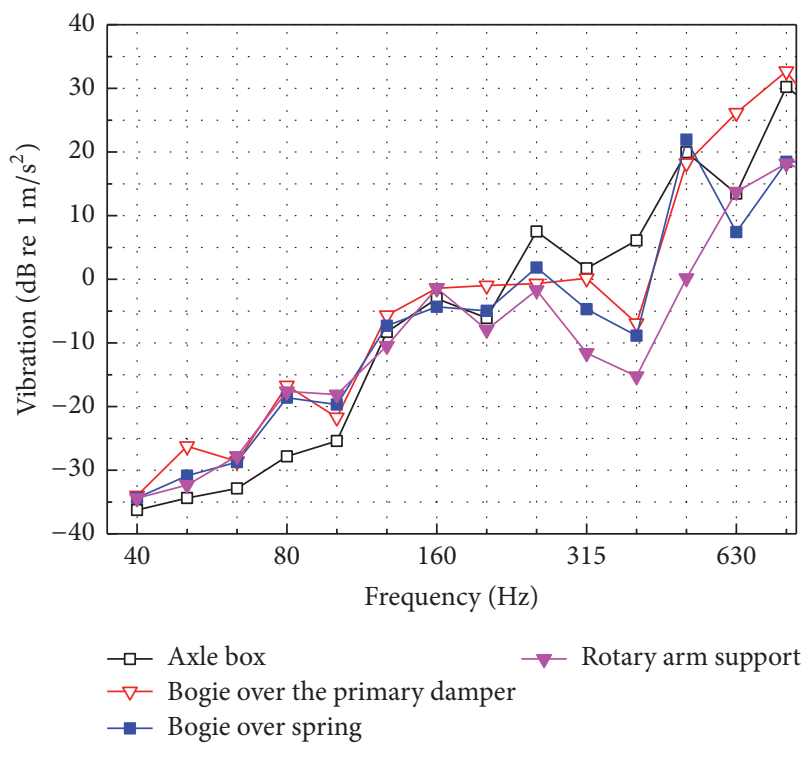

FIGURE 10: Vibration in one-third octave.

are calculated. The responses of the axle box are obtained. All of them are used to evaluate the vibration isolation characteristics from the axle box to the bogie. $H$ is defined as the singular evaluation index of the primary suspensions vibration isolation expressed by

$$
H=10 \log \frac{3 \sum_{f=1}^{800} a_{i}^{2}(f)}{\sum_{f=1}^{800}\left[{a_{o 1}}^{2}(f)+{a_{o 2}}^{2}(f)+{a_{o 3}}^{2}(f)\right]},
$$

where $a_{o 1}, a_{o 2}, a_{o 3}$ are vibration responses of bogie frame near the vertical damping, coil spring, and the rotary arm rubber joint, respectively, and $a_{i}$ is the vibration of axle box.

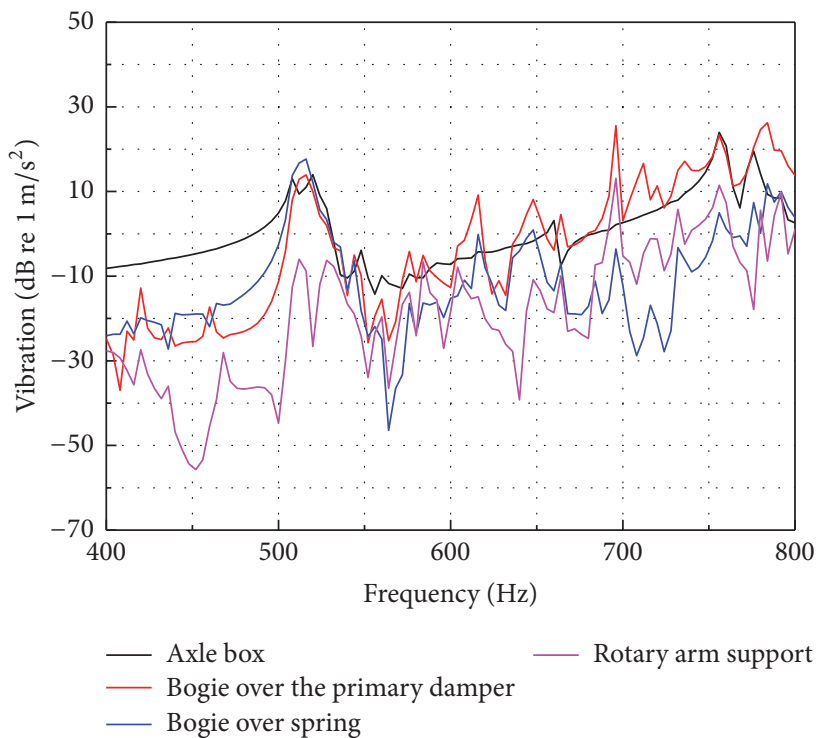

FIGURE 11: Vibration in FFT.

The stiffness and damping of the primary suspension have important influence on the vibration isolation, so three parameters are investigated; they are, respectively, stiffness of the rubber bearing under coil spring, the rotary arm rubber joint, and the damping of the vehicle damper. Beyond that, the radius of wheelset axle and the number of bogie stiffened plates are also considered. Tables 2 and 3 show the vibration isolation singular evaluation index $H$ of those tracks. Table 2 shows that the stiffness of rubber bearing and damping of vertical damper has little effect on the vibration isolation. As the stiffness of rotary arm rubber joint reduces from $220000 \mathrm{~N} / \mathrm{mm}$ to $80000 \mathrm{~N} / \mathrm{mm}$, the overall vibration 


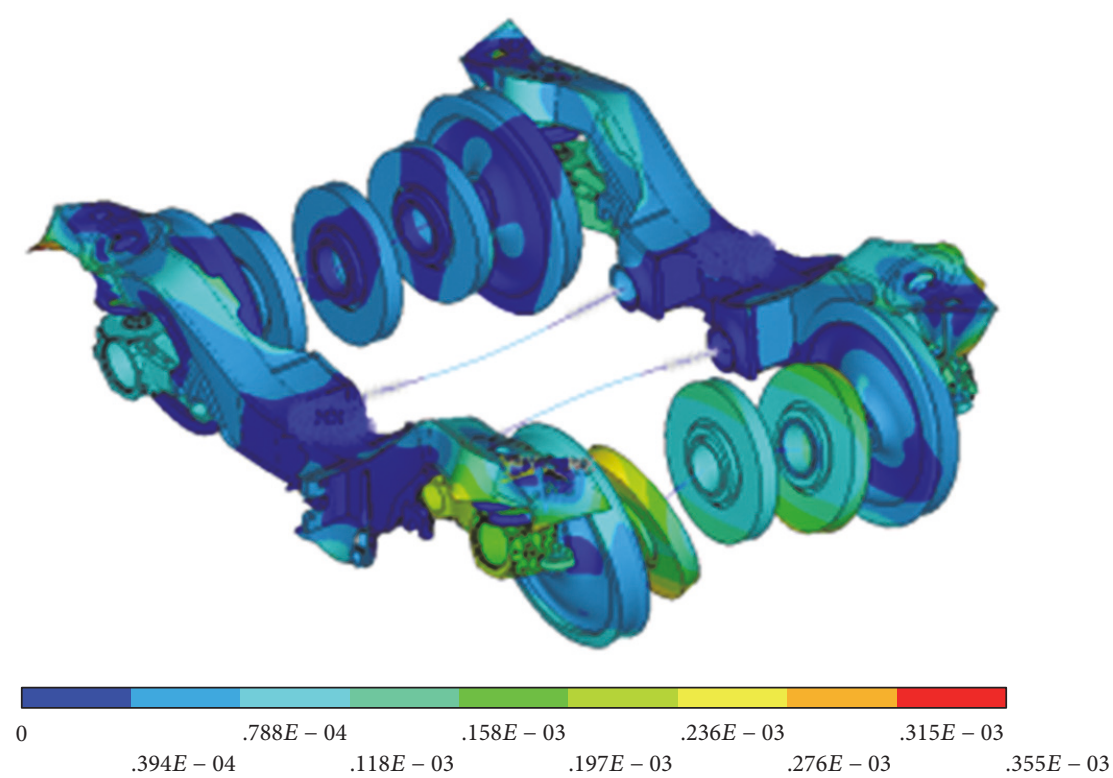

(a) The displacement color clouds of bogie frame in $528 \mathrm{~Hz}$

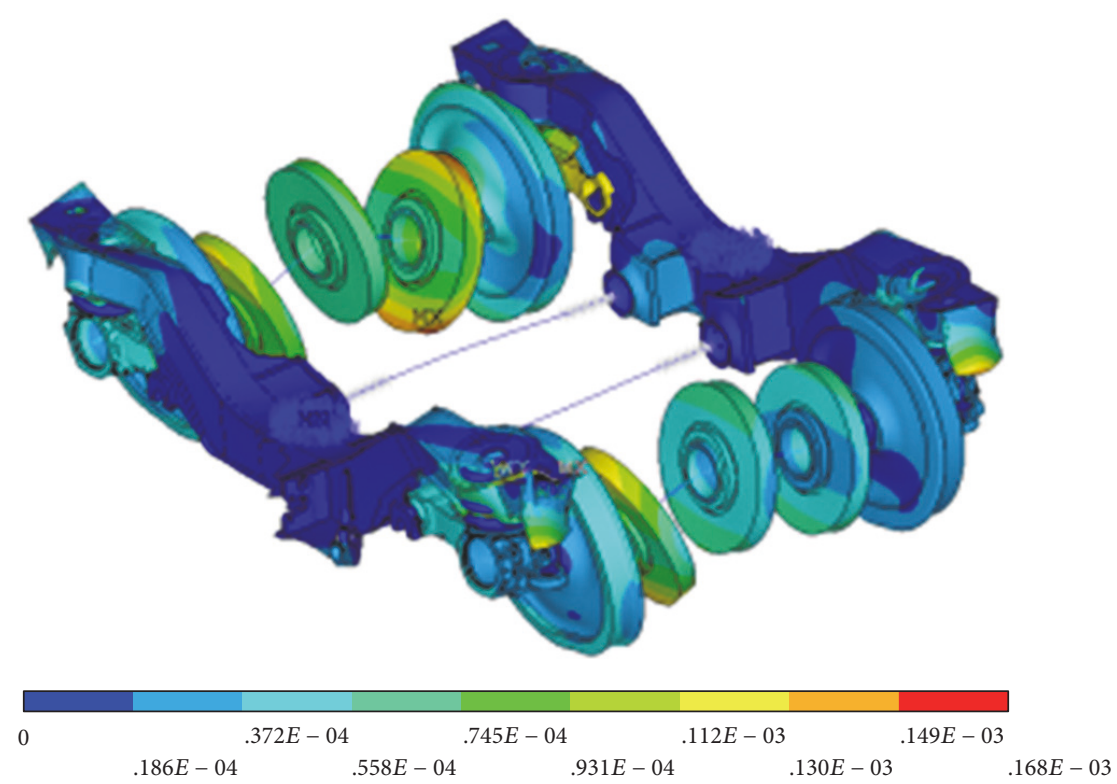

(b) The displacement color clouds of bogie frame in $544 \mathrm{~Hz}$

FIGURE 12: Displacement color clouds of bogie frame in $520 \sim 560 \mathrm{~Hz}$.

TABLE 2: The overall vibration isolation (changing parameters of the primary suspension).

\begin{tabular}{|c|c|c|c|c|c|}
\hline Stiffness of rubber bearing & $H$ & Stiffness of rotary arm rubber joint & $H$ & Damping of vertical damper & $H$ \\
\hline$K=6000$ & 0.69 & $K=220000$ & 3.56 & $C=66$ & 0.63 \\
\hline$K=4000$ & 0.65 & $K=160000$ & 0.65 & $C=33$ & 0.65 \\
\hline$K=2000$ & 0.62 & $K=80000$ & 2.97 & $C=10$ & 0.67 \\
\hline
\end{tabular}




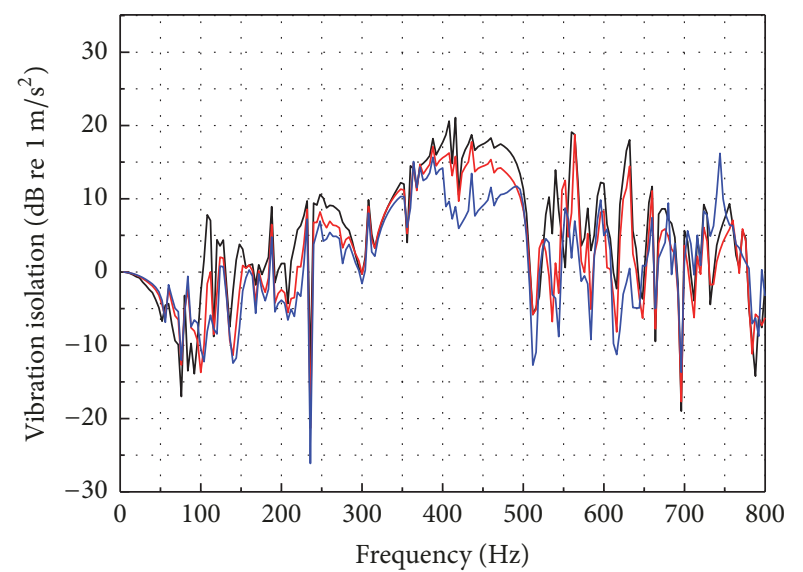

$$
\begin{aligned}
-K & =80000 \\
-K & =160000 \\
-K & =220000
\end{aligned}
$$

(a) Vibration isolation of the primary suspension $(0 \sim 800 \mathrm{~Hz})$

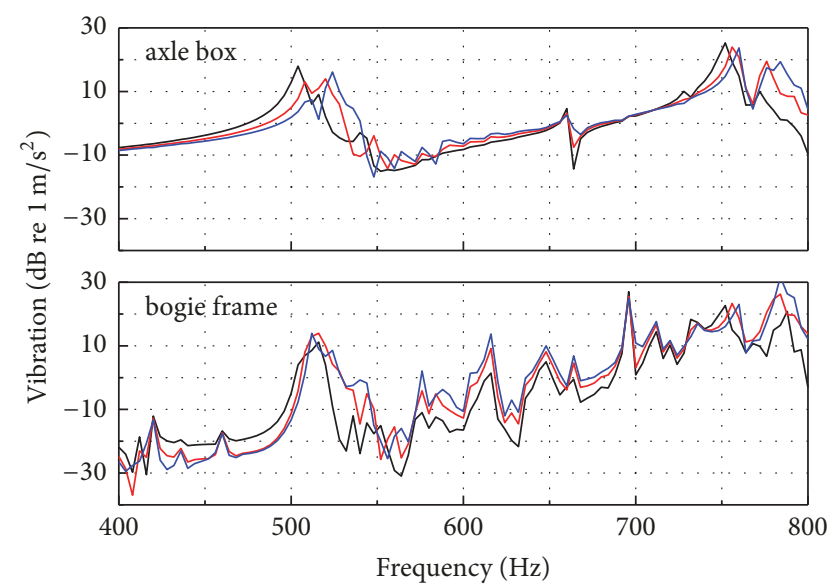

$\begin{aligned} K & =80000 \\ -K & =160000 \\ K & =220000\end{aligned}$

(b) Vibration of bogie frame and axle box $(400 \sim 800 \mathrm{~Hz})$

Figure 13: Different stiffness of the rotary arm rubber joint.

TABLE 3: The overall vibration isolation (changing geometries of the bogie).

\begin{tabular}{lccc}
\hline Radius & $H$ & Stiffened plates & $H$ \\
\hline Original & 0.65 & $N=0$ & 0.65 \\
Add $10 \mathrm{~mm}$ & 2.64 & $N=1$ & 1.68 \\
Add $20 \mathrm{~mm}$ & 3.39 & $N=3$ & 1.70 \\
Sub $10 \mathrm{~mm}$ & -0.08 & $N=5$ & 1.70 \\
\hline
\end{tabular}

isolation decreases by $2.91 \mathrm{~dB}$ at first and then increases by $2.32 \mathrm{~dB}$. Table 3 shows that adding the radius of wheelset axle or numbers of bogie stiffened plates can increase the vibration isolation.

\subsection{Effect of Primary Suspension}

5.1.1. Stiffness of the Rotary Arm Rubber. Compared to the stiffness of the rubber bearing, the stiffness of the rotary arm rubber joint is higher. Therefore, it has an obvious effect on the overall vibration isolation performance as shown in Table 1. As the stiffness increased from $80000 \mathrm{~N} / \mathrm{mm}$ to $160000 \mathrm{~N} / \mathrm{mm}$, the overall vibration isolation decreased by $2.32 \mathrm{~dB}$. As current stiffness increased from $160000 \mathrm{~N} / \mathrm{mm}$ to $220000 \mathrm{~N} / \mathrm{mm}$ continuously, the overall vibration isolation increased by $2.91 \mathrm{~dB}$.

Figure 13(a) shows the spectrums of vibration isolation $H(\omega)$ for the three cases with stiffness $80000 \mathrm{~N} / \mathrm{mm}, 16000 \mathrm{~N} /$ $\mathrm{mm}$, and $220000 \mathrm{~N} / \mathrm{mm}$. A stiffness of $160000 \mathrm{~N} / \mathrm{mm}$ is applied to the actual vehicle. As shown in Figure 13(a), the stiffness of rotary arm rubber joint has an obvious effect on the primary suspension vibration isolation under the frequency domain. The peak positions are almost unchangeable, but the magnitude varies a little under the stiffness of $80000 \mathrm{~N} / \mathrm{mm}, 160000 \mathrm{~N} / \mathrm{mm}$, and $220000 \mathrm{~N} / \mathrm{mm}$. In the case of lower stiffness, the vibration isolation of the primary suspension is worse below $100 \mathrm{~Hz}$ and tends to be the opposite above $100 \mathrm{~Hz}$.

Figure 13(b) shows the vibration spectrums of bogie frame and axle box for the three cases with stiffness $80000 \mathrm{~N} / \mathrm{mm}, 16000 \mathrm{~N} / \mathrm{mm}$, and $220000 \mathrm{~N} / \mathrm{mm}$. As shown in Figure 13(b), as the stiffness decreased, vibration magnitude of axle box is almost unchangeable. However, the peak frequencies decrease in the frequency ranges of $500 \sim 520 \mathrm{~Hz}$ and $750 \sim 780 \mathrm{~Hz}$. Vibration peak positions of bogie frame are almost unchangeable while magnitude decreases gradually with the stiffness decreasing. The vibration isolation between axle box and bogie frame at stiffness of $80000 \mathrm{~N} / \mathrm{mm}$ is better than that of $220000 \mathrm{~N} / \mathrm{mm}$. The maximum vibration isolation between axle box and bogie frame becomes up to approximately $21 \mathrm{~dB}$ in $500 \sim 600 \mathrm{~Hz}$. The bogie frame's resonance frequency in $520 \mathrm{~Hz}$ can escape from axle box of $532 \mathrm{~Hz}$ or $504 \mathrm{~Hz}$.

5.1.2. Stiffness of the Rubber Bearing. The rubber bearing under coil spring is an important vibration absorbing element, which connects the coil spring and the axle box. Its stiffness is lower than other rubber materials of the primary suspension. From Table 2, the stiffness of the rubber bearing has little effect on the vibration isolation, with the stiffness increasing from $2000 \mathrm{~N} / \mathrm{mm}$ to $6000 \mathrm{~N} / \mathrm{mm}$; the overall vibration isolation decreases by $0.07 \mathrm{~dB}$.

Figure 14(a) shows the spectrums of the vibration isolation for the three cases with stiffness $6000 \mathrm{~N} / \mathrm{mm}, 4000 \mathrm{~N} /$ $\mathrm{mm}$, and $2000 \mathrm{~N} / \mathrm{mm}$. Stiffness of $4000 \mathrm{~N} / \mathrm{mm}$ is applied to the actual vehicle. As shown in Figure 14(a), the stiffness of the rubber bearing has almost no effect on the vibration isolation performance above $200 \mathrm{~Hz}$. Below $200 \mathrm{~Hz}$, the peak positions and magnitudes vary a little for different stiffness.

Figure 14(b) shows the vibration spectrums of bogie frame and axle box for the three cases with stiffness $2000 \mathrm{~N} / \mathrm{mm}, 4000 \mathrm{~N} / \mathrm{mm}$, and $6000 \mathrm{~N} / \mathrm{mm}$. As shown in 


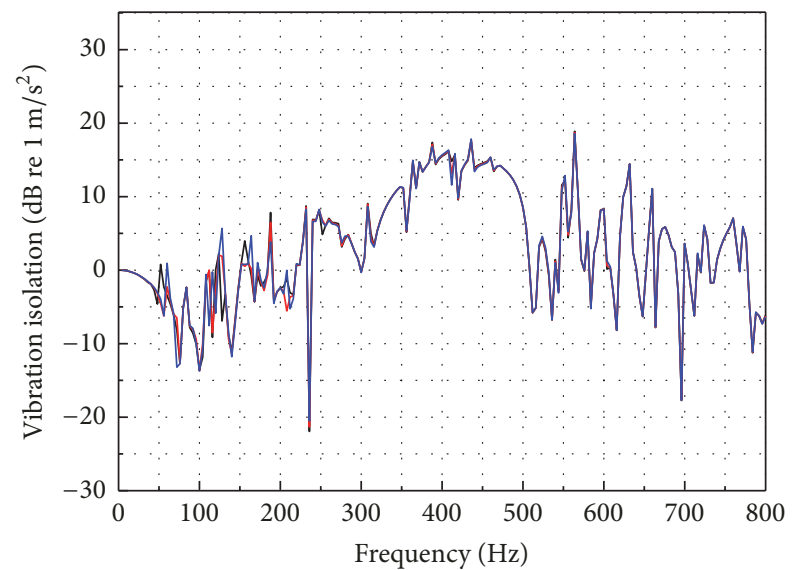

$$
\begin{aligned}
K & =2000 \\
K & =4000 \\
K & =6000
\end{aligned}
$$

(a) Vibration isolation of the primary suspension $(0 \sim 800 \mathrm{~Hz})$

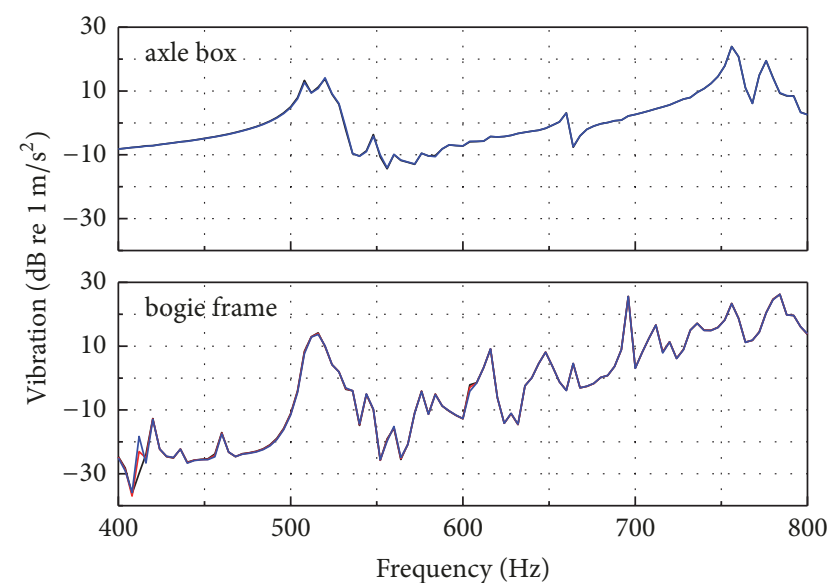

$-K=2000$

$-K=4000$

$-K=6000$

(b) Vibration of bogie frame and axle box $(400 \sim 800 \mathrm{~Hz})$

FIGURE 14: Different stiffness of the rubber bearing under coil spring.

Figure 14(b), as the stiffness decreased, vibrations of axle box and bogie frame are almost unchangeable. Stiffness of the rubber bearing has no effect on the resonance frequency of bogie frame and axle box at $520 \mathrm{~Hz}$.

5.1.3. Damping of the Primary Suspension. As shown above, the stiffness of some components has effects on the vibration isolation. Furthermore, the influences of damping of the primary suspension can be invested. The primary damper can improve the stability and comfortability of railway vehicles; furthermore in this section the effect of the damping on isolation in high frequency is studied. The damping of the primary suspension parts mainly depends on the vertical damper and the rubber material damping. As for the damping of the rubber material, it is hard to get, so this paper mainly invests the influence of the vertical damper. In Table 2, the damping of the vertical damper has little effect on the vibration isolation, with the damping increasing from $10 \mathrm{~N} \cdot \mathrm{s} / \mathrm{mm}$ to $66 \mathrm{~N} \cdot \mathrm{s} / \mathrm{mm}$ and the overall vibration isolation decreasing by $0.04 \mathrm{~dB}$.

Figure 15(a) shows the spectrums of the vibration isolation for the three cases with damping $66 \mathrm{~N} \cdot \mathrm{s} / \mathrm{mm}, 33 \mathrm{~N} \cdot \mathrm{s} / \mathrm{mm}$, and $10 \mathrm{~N} \cdot \mathrm{s} / \mathrm{mm}$, respectively. Damping of $33 \mathrm{~N} \cdot \mathrm{s} / \mathrm{mm}$ is applied to the actual vehicle. As shown in Figure 15(a), damping has a little effect on the vibration isolation. As for the different damping, peak positions and magnitudes of peaks are almost unchanged above $300 \mathrm{~Hz}$. Below $300 \mathrm{~Hz}$, lower damping, the vibration isolation of the primary suspension is worse. Therefore, it is not a good way to apply the low damping to decrease vibration of high-speed vehicle system in mid and high frequency.

Figure 15(b) shows the vibration spectrums of bogie frame and axle box for the three cases with damping $10 \mathrm{~N} \cdot \mathrm{s} / \mathrm{mm}, 33 \mathrm{~N} \cdot \mathrm{s} / \mathrm{mm}$, and $66 \mathrm{~N} \cdot \mathrm{s} / \mathrm{mm}$. As shown in Figure 15(b), as the damping decreased, vibrations of axle box and bogie frame are almost unchangeable. Damping of the primary damper has no effect on the resonance frequency of bogie frame and axle box at $520 \mathrm{~Hz}$.

5.2. Effect of Bogie's and Wheelset's Geometries. The coupled resonance of wheelset and bogie frame at $520 \mathrm{~Hz}$ may be the main reason which leads to the high-order wheel polygon, so the vibration in high frequency may be reduced by improving the structure of these two components.

5.2.1. Radius of the Wheelset Axle. Because of the high weigh, wheelset can generate large vibration energy once its model is excitated, which lead to the serious wheel-rail force. In the frequency band of $520 \sim 550 \mathrm{~Hz}$. the model deformation of wheelset is shown as the third bend of axle, So this mode can be improved by changing the radius of the wheelset axle. From Table 2, the radius of the wheelset axle has obvious effect on the vibration isolation. As the radius increases by $10 \mathrm{~mm}$ and $20 \mathrm{~mm}$, the overall vibration isolation increases by $1.99 \mathrm{~dB}$ and $2.74 \mathrm{~dB}$ respectively, while as the radius decreases by $10 \mathrm{~mm}$, the overall vibration isolation decreases by $0.73 \mathrm{~dB}$.

Figure 16(a) shows the spectrums of the vibration isolation for the four cases with original radius and improved radius, which include adding $10 \mathrm{~mm}$, adding $20 \mathrm{~mm}$, and reducing $10 \mathrm{~mm}$, respectively. As shown in Figure 16(a), the radius of wheelset has almost no effect on the vibration isolation under $500 \mathrm{~Hz}$, while vibration isolation magnitude shows a big fluctuation above $500 \mathrm{~Hz}$.

Figure 16(b) shows the vibration spectrums of bogie frame and axle box for the four cases with different radiuses, which include adding $10 \mathrm{~mm}$, adding $20 \mathrm{~mm}$, decreasing $10 \mathrm{~mm}$, and the original radius, respectively. As shown in Figure 16(b), as the radius increases, vibration magnitudes of axle box and bogie frame decrease in the frequency band of $400 \sim 530 \mathrm{~Hz}$ and $570 \sim 800 \mathrm{~Hz}$ and tend to be opposite in 


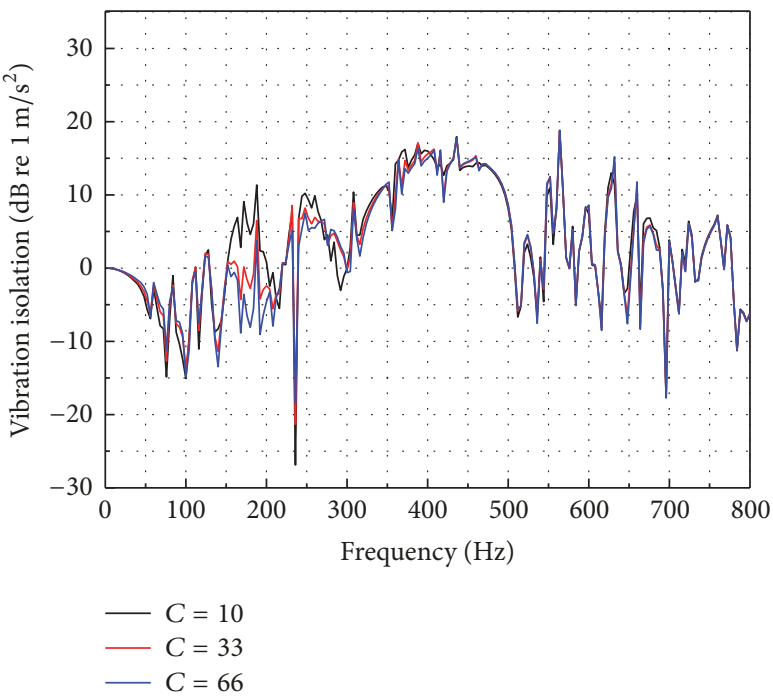

(a) Vibration isolation of the primary suspension $(0 \sim 800 \mathrm{~Hz})$

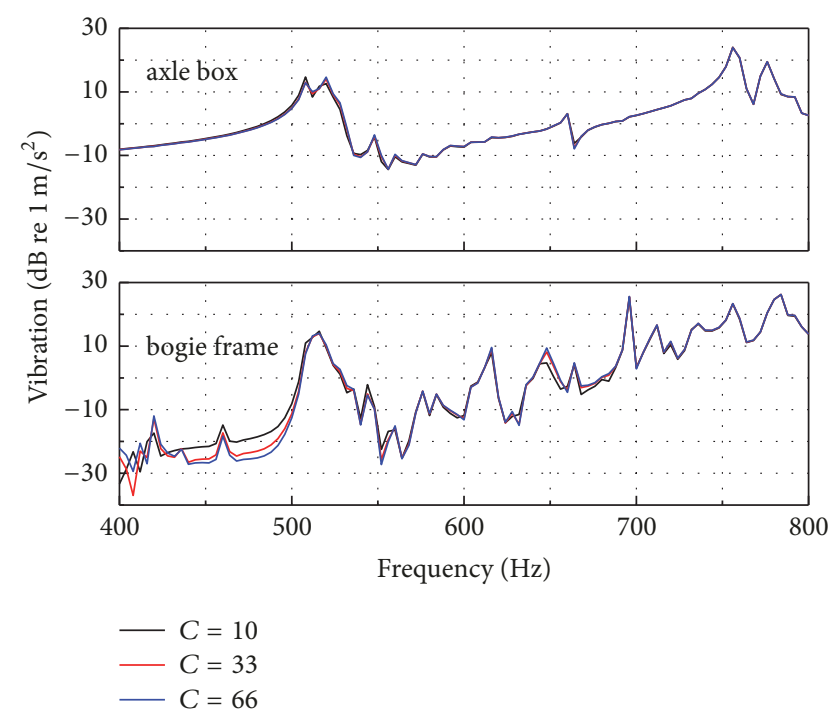

(b) Vibration of bogie frame and axle box $(400 \sim 800 \mathrm{~Hz})$

FIGURE 15: Different dampings of the vertical damper.

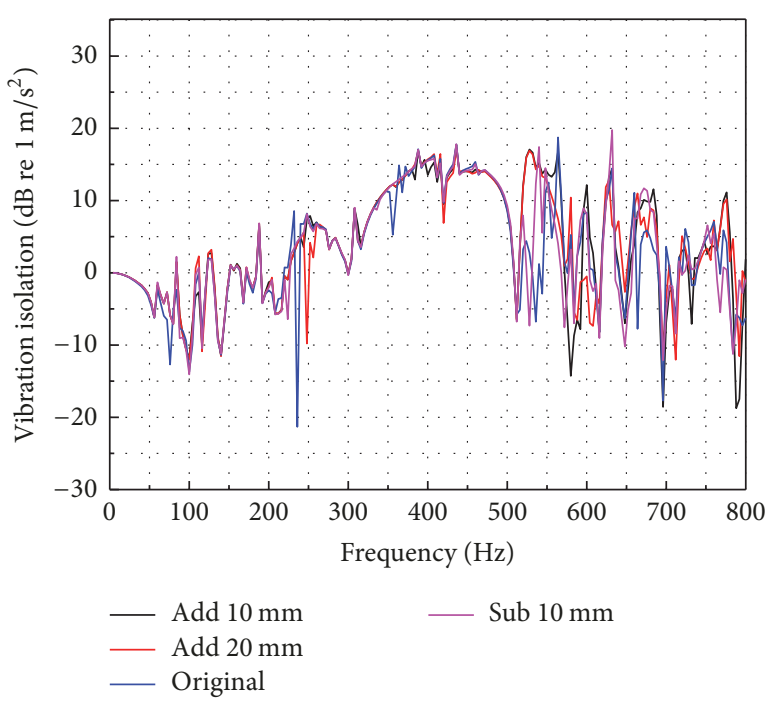

(a) Vibration isolation of the primary suspension $(0 \sim 800 \mathrm{~Hz})$

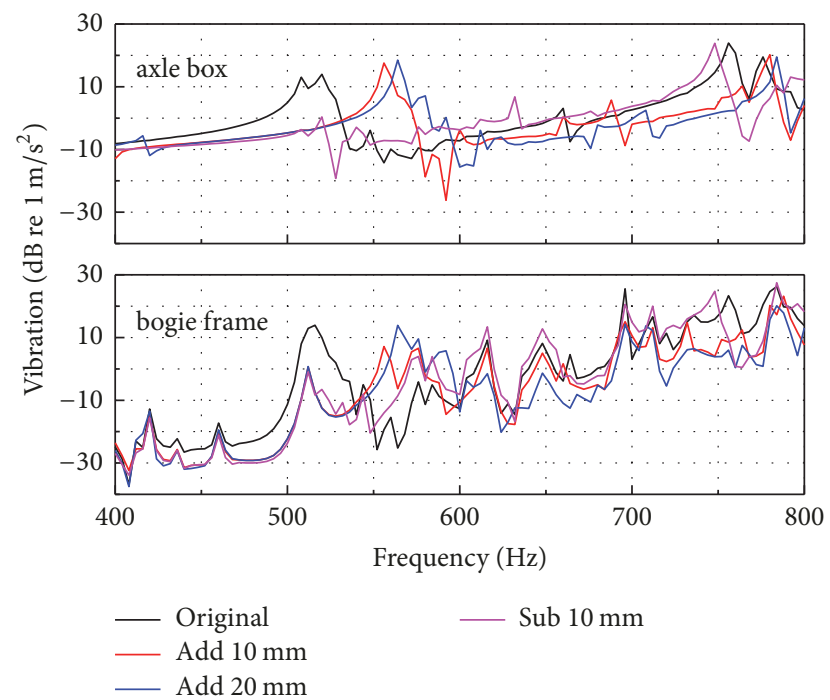

(b) Vibrations of bogie frame and axle box $(400 \sim 800 \mathrm{~Hz})$

FIGURE 16: Different radiuses of the wheelset axle.

the range of $530 \sim 570 \mathrm{~Hz}$. With the radius adding $10 \mathrm{~mm}$, peak frequency at $520 \mathrm{~Hz}$ of axle box increases by $40 \mathrm{~Hz}$, but bogie frame generates peak at the same frequency which is at $560 \mathrm{~Hz}$. While radius proceeds to add $20 \mathrm{~mm}$, peak frequency at $560 \mathrm{~Hz}$ of axle box increases by $10 \mathrm{~Hz}$ and bogie frame generates peaks at $570 \mathrm{~Hz}$. Based on the original radius, the radius deceases by $10 \mathrm{~mm}$ and peak frequency at $520 \mathrm{~Hz}$ of axle box diminishes, but bogie frame has not generate any peak at the same frequency and the magnitude at $520 \mathrm{~Hz}$ decreases obviously. In a whole, adding the radius of wheelset axle is not an effective way to avoid the high resonance. Because it will make the resonance peak of axle box and bogie frame move at the same time and bring in new problems of resonances at $560 \mathrm{~Hz}$ and $570 \mathrm{~Hz}$. However, decreasing radius may be a good way to reduce high frequency vibration because it can reduce the magnitudes of axle and bogie frame at the same time and improve the vibration isolation. Meanwhile new vibration peak cannot be generated.

5.2.2. Bogie with Stiffened Thin Plates. Because of the high weigh, bogie frame can generate large vibration energy once its model is excitated. Then the wheel-rail force and the vibration increase dramatically. Modal shapes of bogie frame in low orders are almost shown as the global deformations; as the modal frequencies increase, side beams' and horizon beams' local deformations become dominant. In the frequency range of $520 \sim 550 \mathrm{~Hz}$, the modal shapes are always shown as the local movements of the end of side beams. Thus, 


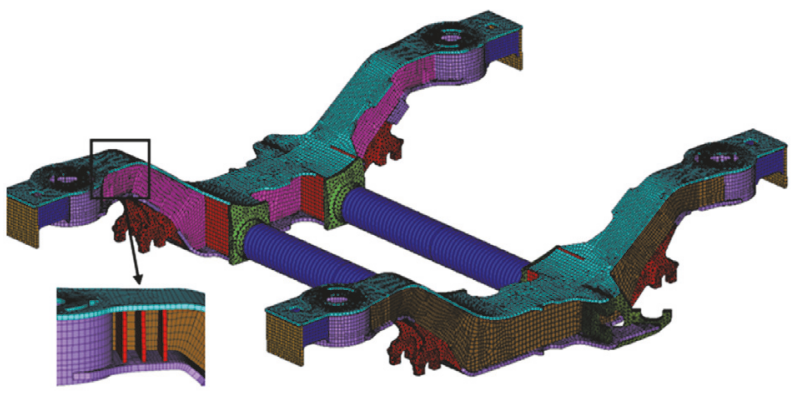

Figure 17: Stiffened plates of bogie.

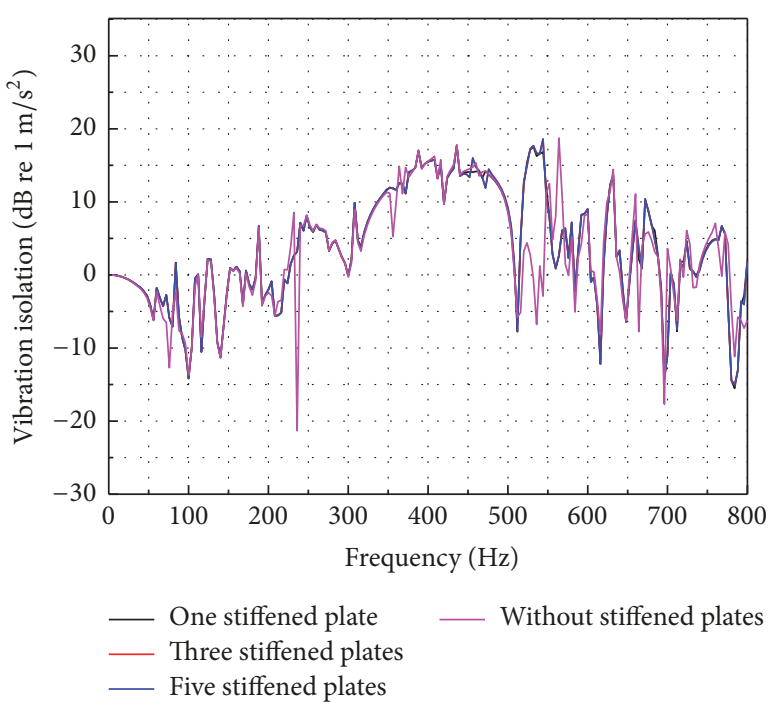

(a) Vibration isolation of the primary suspension $(0 \sim 800 \mathrm{~Hz})$

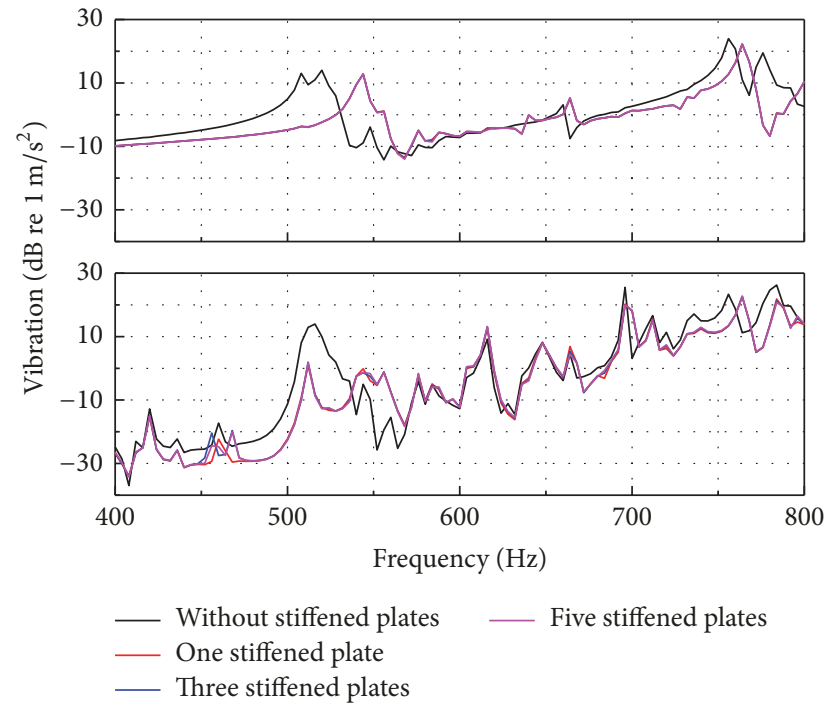

(b) Vibration of bogie frame and axle box $(400 \sim 800 \mathrm{~Hz})$

FIGURE 18: Different numbers of the stiffened thin plates.

adding stiffened thin plates in the side beams can improve the local stiffness of bogie frame and then change these modal frequencies. The stiffened thin plates are located in the middle of the upper covers, lower covers, outside covers, and inside covers, and numbers are one, three, and five, respectively. Figure 17 shows the positions of stiffened thin plates.

From Table 2, after adding stiffened plates, the overall vibration isolation increases by $1.03 \mathrm{~dB}$, but as the numbers increase, the overall vibration isolation almost varies a little.

Figure 18(a) shows the spectrums of the vibration isolation for the four cases with original bogie frame and after adding stiffened thin plates, which include one plate, three plates, and five plates, respectively. As shown in Figure 18(a), the vibration isolation increases in $520 \sim 550 \mathrm{~Hz}$ and $672 \mathrm{~Hz}$ after adding stiffened plates while the vibration isolation decreases in $550 \sim 570 \mathrm{~Hz}$. Other frequencies are almost unchangeable. Different numbers of stiffened plates almost have no effect on the vibration isolation in the frequency band.

Figure 18(b) shows the vibration spectrums of bogie frame and axle box for the four cases with different numbers of stiffened plates. As shown in Figure 18(b), the vibration peaks of axle box at $520 \mathrm{~Hz}$ increase by $30 \mathrm{~Hz}$ after adding the stiffened thin plates. Bogie frame vibration peaks at $520 \mathrm{~Hz}$ have not changed, in which magnitudes decrease by $12.33 \mathrm{~dB}$. And the magnitudes of bogie frame at $550 \mathrm{~Hz}$ vary a little. Different numbers of stiffened plates have no effect on the vibration of bogie frame and axle box, so adding stiffened thin plates is an effective way to improve the vibration isolation of the whole bogie at $520 \mathrm{~Hz}$, and only one number can be satisfied.

\section{Conclusions}

To reduce the vibration of the bogie in the mid and high frequency, a 3D flexible model of a whole bogie is developed using the explicit finite element (FE) method. Then the influences of material and structure parameters on bogie are analyzed carefully. Based on the obtained results, the following conclusions are drawn:

(1) The field tests show that the mid and high frequency vibrations of high-speed bogies are very notable, especially in the $560 \sim 590 \mathrm{~Hz}$ range, which are very close to the passing frequencies corresponding to the 22nd to 23rd polygonal wear of the wheel. 
(2) Based on the roughness and receptance by site test, the wheel/rail contact forces are calculated as the FE model's input. Then vibrations of the axle box and the bogie frame obtained by simulation are in good agreement with the measured results. Thus, the FE model and the calculated method are validated effectively.

(3) The vibration responses of the bogie FE model are calculated by the harmonic response analysis. The numerical results show that magnitudes of serious vibrations on the axle box are close to that of the bogie frame in the frequency band of $520 \sim 560 \mathrm{~Hz}$. The vibration deformations of the whole bogie in the frequency band of $520 \sim 560 \mathrm{~Hz}$ are mainly shown as the couple vibration of bogie side beam local movements and the third bend of wheelset. The couple vibrations of bogie frame and wheelset may be the main reasons which lead to the resonance vibration in high frequency and then induce the high-order wear of wheel.

(4) The numerical results show that stiffness of the rubber bearing and damping of the primary damper have little effect on the vibrations of the bogie frame and axle box, while the resonance peaks in high frequency range can be reduced by reducing the stiffness of axle box rotary arm joint, reducing the wheelset axle radius, or strengthening the bogie frame location.

\section{Conflicts of Interest}

The authors declare that they have no conflicts of interest.

\section{Acknowledgments}

The present work was supported by the National Key R\&D Program of China (nos. 2016YFB1200503-02, 2016YFB1200506-08, 2016YFE0205200), the National Natural Science Foundation of China (nos. U1434201, U1734201, 51475390), and the Scientific Research Foundation of State Key Laboratory of Traction Power, China (no. 2015TPL_T08).

\section{References}

[1] G. Han, J. Zhang, X. Xiao, D. Cui, and X. Jin, "Study on highspeed train abnormal interior vibration and noise related to wheel roughness," Jixie Gongcheng Xuebao/Journal of Mechanical Engineering, vol. 50, no. 22, pp. 113-121, 2014.

[2] K. Popp, H. Kruse, and I. Kaiser, "Vehicle-track dynamics in the mid-frequency range," Vehicle System Dynamics, vol. 31, no. 5-6, pp. 423-464, 1999.

[3] P. Alexander, S. Stefan, A. Roder et al., "Active vibration control for high speed train bogies," Smart Mater Structure, vol. 14, pp. 1-18, 2005.

[4] Z.-S. Ren, G. Yang, S.-S. Wang, and S.-G. Sun, "Analysis of vibration and frequency transmission of high speed EMU with flexible model," Acta Mechanica Sinica, vol. 30, no. 6, pp. 876883, 2014.

[5] J. Zhang, G. Han X, and X. Xiao B, "Influence of wheel polygonal wear on interior noise of high-speedtrains," Zhejiang UniversityScience (Applied physics \& Engineering), vol. 15, no. 12, pp. 10021018, 2014.
[6] M. Sjoberg, On Dynamic Properties of Rubber Isolators [Ph.D. thesis], The Royal Institute of Technology, Sweden, 2002.

[7] S. Bruni, J. Vinolas, M. Berg, O. Polach, and S. Stichel, "Modelling of suspension components in a rail vehicle dynamics context," Vehicle System Dynamics, vol. 49, no. 7, pp. 1021-1072, 2011.

[8] Y. X. Chen, An experimental and theoretical investigation of the dynamic properties of rubber [Ph.D. thesis], Southwest Jiaotong University, Chengdu, China, 2008.

[9] P. J. Remington, "Wheel/rail noise part I: characterization of the wheel/rail dynamic system," Journal of Sound and Vibration, vol. 46, no. 3, pp. 359-379, 1976.

[10] D. J. Thompson, "Wheel-rail noise generation, Part I: Introduction and interaction model," Journal of Sound and Vibration, vol. 161, no. 3, pp. 387-400, 1993. 


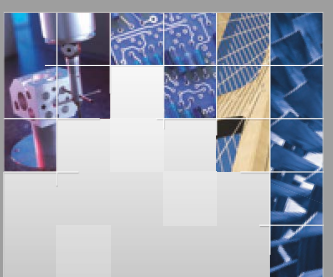

\section{Enfincering}
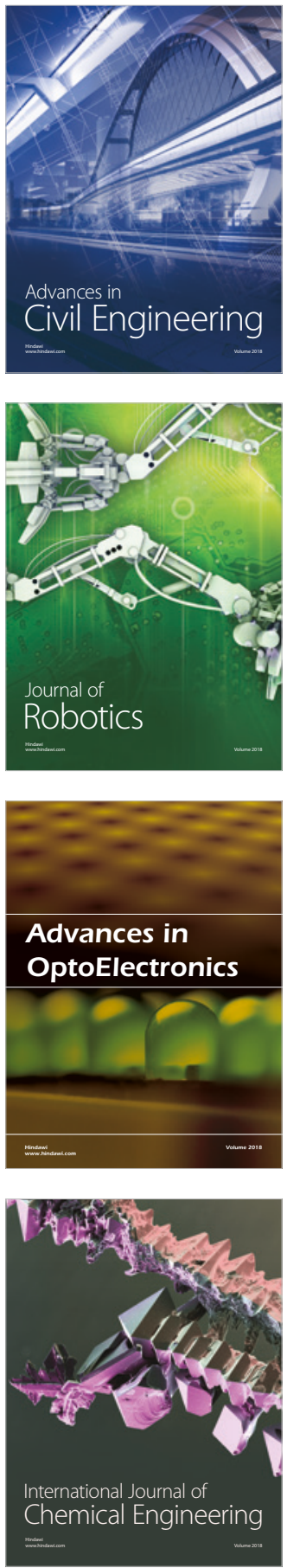

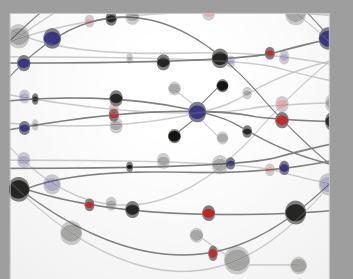

\section{Rotating \\ Machinery}

The Scientific World Journal

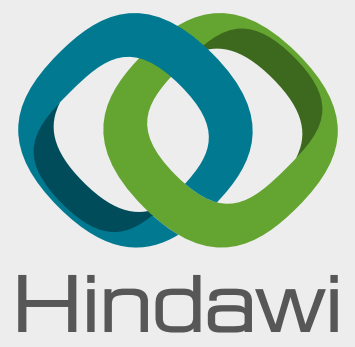

Submit your manuscripts at

www.hindawi.com
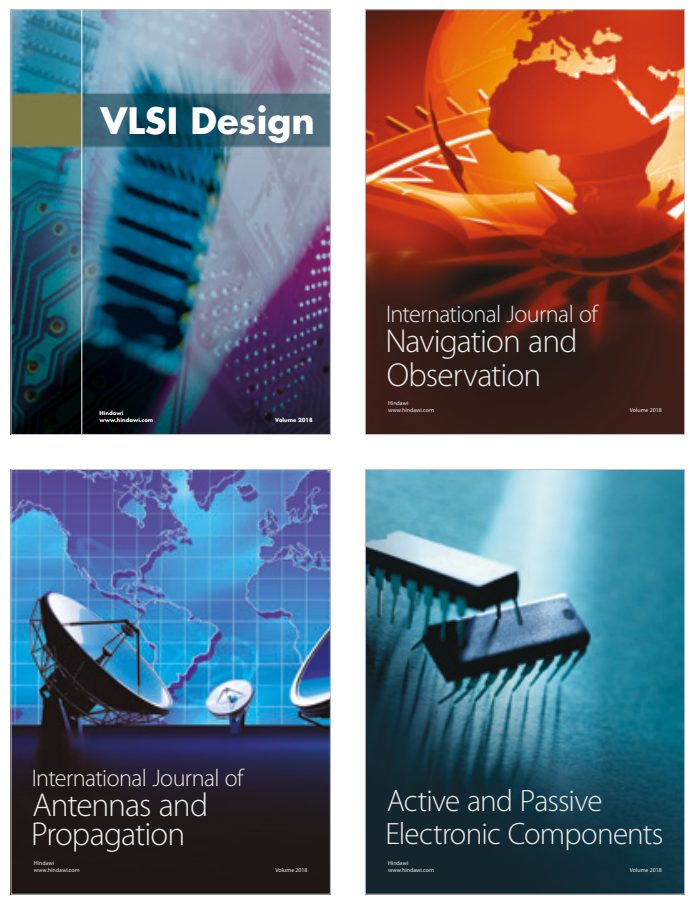
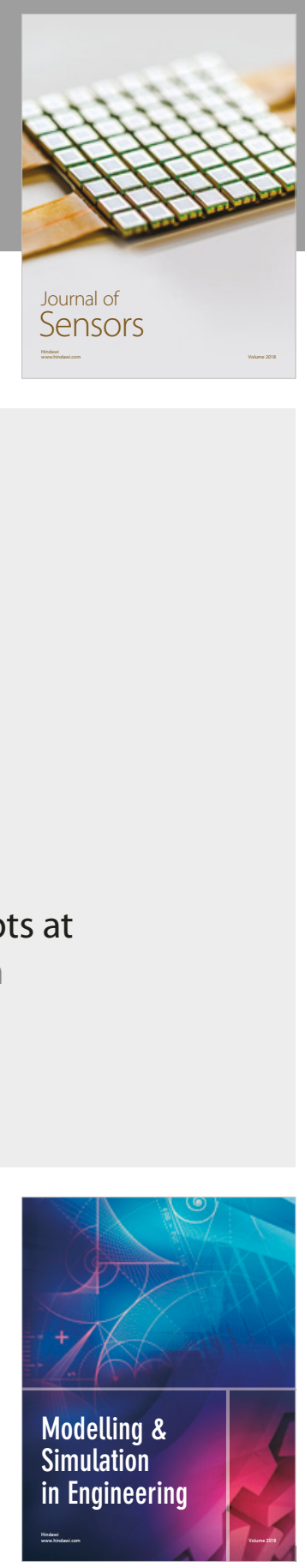

\section{Advances \\ Multimedia}
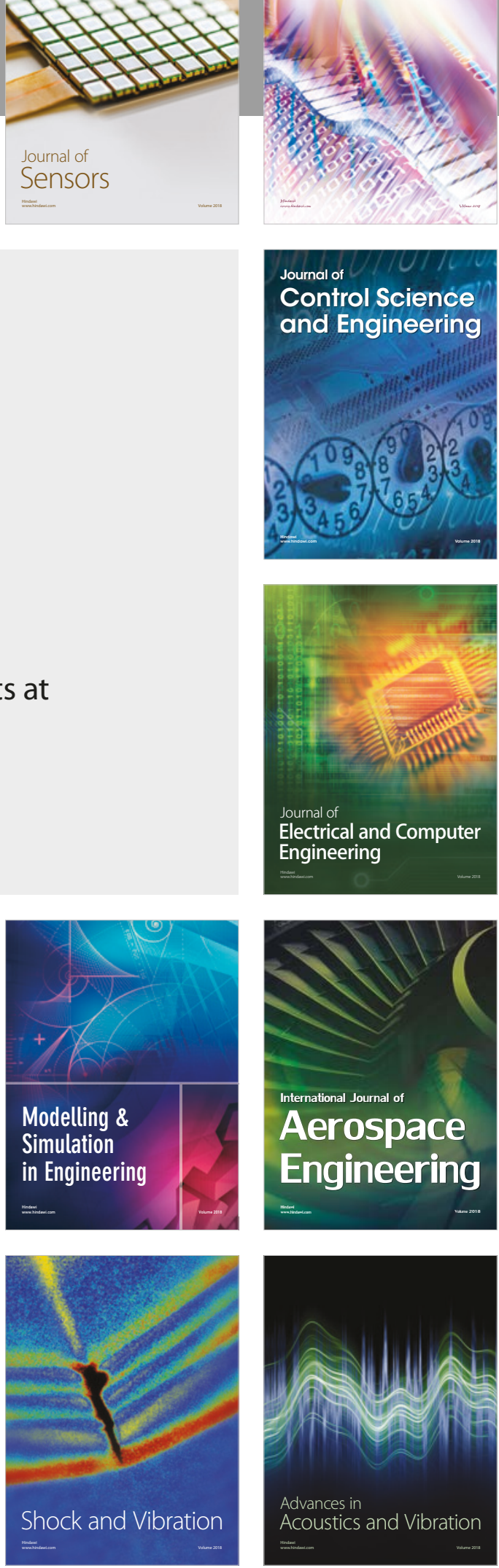